\title{
ORIGINAL ARTICLE Use of Medihoney as a non-surgical therapy for chronic pressure ulcers in patients with spinal cord injury
}

\author{
B Biglari ${ }^{1}, \mathrm{PH}$ vd Linden ${ }^{2}$, A Simon ${ }^{3}$, S Aytac ${ }^{2}, \mathrm{HJ} \mathrm{Gerner}^{4}$ and A Moghaddam ${ }^{2}$
}

Study design: Prospective, observational study of 20 spinal cord-injured ( $\mathrm{SCl}$ ) patients with chronic pressure ulcers (PUs) using Medihoney. Objectives: To determine the effects of Medihoney by bacterial growth, wound size and stage of healing in PUs.

Methods: We treated $20 \mathrm{SCl}$ adult patients with chronic PUs using Medihoney. In all, 7 patients (35\%) were female, and 13 (65\%) were male. The average patient age was 48.7 years (30-79). In all, 6 patients (30\%) were tetraplegic and 14 (70\%) were paraplegic. Also, 5 patients (25\%) had grade IV ulcers and 15 patients (75\%) had grade III ulcers according to the National Pressure Ulcer Advisory Panel.

Results: After 1 week of treatment with Medihoney, all swabs were void of bacterial growth. Overall 18 patients (90\%) showed complete wound healing after a period of 4 weeks, and the resulting scars were soft and elastic. No negative effects were noted from the treatment using Medihoney. No blood sugar level derailment was documented.

Conclusion: The medical-honey approach to wound care must be part of a comprehensive conservative surgical wound-care concept. Our study indicates the highly valuable efficacy of honey in wound management and infection control as measured by bacterial growth, wound size and healing stage.

Spinal Cord (2012) 50, 165-169; doi:10.1038/sc.2011.87; published online 20 September 2011

Keywords: pressure ulcer; paraplegics; MRSA; spinal cord-injured; Medihoney; medical honey

\section{INTRODUCTION}

Pressure ulcers (PUs) are among the most common complications in patients with spinal cord injury. ${ }^{1,2}$ In Europe, the medical treatment costs of patients with PUs are 2.5 times higher than the treatment costs of patients without PUs. Current reports show an increasing incidence of PUs: $9.2 \%$ in $1989,15.5 \%$ in 2003 and $10 \%$ in $2004 .^{3}$

The long-term immobilisation and the lack of innervation result in muscle atrophy and lead to a decrease in the soft tissue coverage of bony structures. The remaining soft tissue, which is reduced in thickness, can no longer withstand the pressure and, in conjunction with poor wound healing, a PU may result.

Similarly, the emergence of decubitus is promoted by the absent sensitive innervation of the skin, because, due to this, the patient concerned fails to notice the progression of the PU. The main problem in clinical practice is the deep and extended soft tissue damage and necrosis and the bacterial super infection. These are not only a challenge for the surgeon, but can also lead to life-threatening complications.

$\mathrm{PU}$ is a lifelong health risk for paraplegic patients and can recur. Therefore, in order to withstand this, they require intensive care and modern technical equipment. Because of the need for lifelong therapy, the surgical procedure must be planned in advance and carefully. Here additive methods could be helpful.

The decision regarding surgical or non-surgical closure of ulcers depends on the size, depth, localisation, bacterial colonisation of the defect, the age and the general health of the patient, as well as on the duration of existence of the PU. Dry necrosis is debrided surgically.
Wound dressings should absorb surplus secretions, facilitate gas exchange, form a barrier to microorganisms and be readily removable. Further therapies include enzymatic cleaning and the application of hydrocolloidal plates or hydroactive dressings such as Alginate, with the shared goal of obtaining optimal wound healing.

With hospitals facing the problem of increasing bacterial resistance and presence of biofilms, ${ }^{4}$ it is important to have antiseptic concepts.

In this manner, an ideal wound antiseptic should meet the following criteria: ${ }^{5}$

A rapid onset of bactericidal action and a remnant broad-spectrum effect against bacteria and fungi, even under the unfavourable conditions of exudating colonised or infected wounds.

- Enhancement and acceleration of the physiological process of wound healing (debridement, granulation), even if applied for prolonged periods.

- No adverse local or systemic effects (allergy, toxicity related to absorption).

- A moderate cost even if applied two times daily.

This report represents a series of professional wound care with medical-grade honey in spinal cord-injured (SCI) patients with PUs.

\section{MATERIALS AND METHODS}

This study was a nine-centre, prospective, observational and open-label study, conducted between March 2007 and March 2009. It was initiated and

${ }^{1}$ Abteilung für Querschnittgelähmte und Technische Orthopädie der BG-Unfallklinik, Ludwigshafen, Germany; ${ }^{2}$ Klinik für Orthopädie und Unfallchirurgie der BG-Unfallklinik, Ludwigshafen, Germany; ${ }^{3}$ Children's Hospital Medical Center, University of Bonn, Bonn, Germany and ${ }^{4}$ Department of Orthopedics, Trauma Surgery and Paraplegiology, Heidelberg University Hospital, Heidelberg, Germany

Correspondence: Dr B Biglari, Abteilung für Querschnittgelähmte und Technische Orthopädie der BG-Unfallklinik, Ludwig-Guttmann Straße 13, 67071 Ludwigshafen, Germany. E-mail: biglari@bgu-ludwigshafen.de

Received 6 October 2010; revised and accepted 17 July 2011; published online 20 September 2011 
coordinated by the Department of Paediatric Haematology and Oncology at the University Hospital of Bonn. Financial support was obtained from the manufacturer of the Medihoney products, who did not have any influence on data collection, analysis or publication parameters.

Ethical approval was gained for this study from the Ethics Committee of the Medical Faculty of the Rheinische Friedrich-Wilhelms-University of Bonn (No. 025/05); this approval was applied to all participating centres. In our Center (Department of paraplegiologie of BG Trauma centre in Ludwigshafen, Germany), we participated from January 2008 to November 2008 in this study. In all, 20 adult patients with chronic PUs and spinal cord injuries of different levels received Medihoney treatment for more than 6 weeks. The PUs differed in size, depth, grade and bacterial colonisation. Each patient had previously undergone unsuccessful PU treatment with alternate dressings for a minimum of 12 weeks. The Medihoney dressings were changed daily in a sterile environment. Overall, 7 patients $(35 \%)$ were female and $13(65 \%)$ were male. The average age was 48.7 years (30-79). A total of 6 patients (30\%) were tetraplegic and $14(70 \%)$ were paraplegic. Overall, 15 patients (75\%) were completely paralysed and 5 patients were (25\%) incompletely paralysed. In all,5 patients (25\%) had grade IV ulcers, and 15 patients (75\%) had grade III ulcers according to the National Pressure Ulcer Advisory Panel classification. ${ }^{6}$ All patient wounds were documented with weekly photographs.

The honey used for this study was Medihoney antibacterial honey (Comvita, New Zealand), which is listed on the Australian Register of Therapeutic Goods for the treatment of acute and chronic wounds. This honey has been gammairradiated to kill clostridium spores without affecting the in vitro anti-bacterial effect of the honey. ${ }^{7}$

The Medihoney dressings were prepared by application of the honey to a non-adherent sterile contact layer that was placed on top of a sterile dressing pad. The honey was applied at a thickness of approximately $3 \mathrm{~mm}$ and conformed to the shape of the ulcers.

\section{RESULTS}

We treated 20 SCI adult patients with chronic PUs of different sizes, depths, grades and degrees of bacterial colonisation with Medihoney from January 2008 until November 2008. In all, 7 patients (35\%) were female, and $13(65 \%)$ were male. The average patient age was 48.7 years (30-79). A total of 6 patients $(30 \%)$ were tetraplegic and 14 (70\%) were paraplegic. Overall, 15 patients (75\%) were completely paralysed, and $5(25 \%)$ were partially paralysed.
Table 1 shows the levels of spinal cord damage, ulcer localisation, size, age, sex, wound colonisation and ulcer grade.

All patients treated with Medihoney had suffered from 1-2 chronic PUs for more than 3 months; 5 patients (25\%) had grade IV ulcers, and $15(75 \%)$ had grade III ulcers. In all patients, the wound surface was measured using square transparent films that measured $0.5 \times 0.5 \mathrm{~cm}^{2}$. The average PU size was $21.7 \mathrm{~cm}^{2}\left(8-80 \mathrm{~cm}^{2}\right)$.

A total of 5 patients (25\%) underwent surgical necrotomy owing to very dry necrosis. The ulcer locations were sacral (45\%), leg (20\%), heel (10\%), ischial (15\%), groin (5\%) and thigh (5\%). Sterile swabs of the wound surface were taken daily using standard microbiological culture methods ${ }^{8}$ (Figures 1a-c).

During treatment with Medihoney, PUs were documented at 3-week intervals. During the examinations, the ulcers were photographed, measured and cultured. All PUs were treated once daily with Medihoney after being cleaned with sterile Ringer's solution. The surrounding skin was disinfected with either Octenisept (Octenidinhydrochloride $0.1 \%$, Phenoxyethanole $3 \%$; Schülke, Norderstedt, Germany) or Octeniderm (Octenidinehydrochloride 0.1 Vol\%, 1Propanol 30 Vol\%, 2-Propanol 45 Vol\%; Schülke). Care was taken to avoid contact between the wound surface and the disinfectant. No antibiotic treatment was given simultaneously to the Medihoney treatment to avoid any outside influences on the therapeutic effect of the honey.

After 1 week of treatment with Medihoney, all swabs were void of bacterial growth. A total of 18 patients (90\%) showed complete wound healing after a period of 4 weeks. Resulting scars were soft and elastic (Figures $2 \mathrm{a}-\mathrm{c}$ and $3 \mathrm{a}-\mathrm{c}$ ). No negative effects were noted from treatment with Medihoney. No blood sugar level derailment was documented in diabetic patients, despite the daily application of large amounts of honey. No allergic reactions were noted.

\section{DISCUSSION}

Our study, the first comprehensive case series of 20 SCI adult patients with chronic PUs, demonstrates the feasibility and effectiveness of

Table 1 Show the features of the patients

\begin{tabular}{|c|c|c|c|c|c|c|c|c|}
\hline Patient & Gender & Lesion level & Localisation & Franke/13 & Grading 6 & Bacterial. colonisation & Size & Age (years) \\
\hline 1 & M & Th4 & Sacrum & $A$ & III & Staph. epi. & 35 & 79 \\
\hline 2 & M & Th1 & Ischium and scrotal & B & III & Klebs. Pneumo. & 80 & 35 \\
\hline 3 & M & Th12 & Heel & $A$ & III & Staph. aur., Pseud. aeru. & 8 & 78 \\
\hline 4 & $\mathrm{~F}$ & Th8 & Leg & $A$ & IV & Enterb. cloa., Prot. mib., Staph. aur. & 50 & 44 \\
\hline 5 & M & $\mathrm{C7}$ & Sacrum & $\mathrm{B}$ & III-IV & Staph. epi., Hae. str. gr. F Klebs, Pseud. aeru. & 19 & 50 \\
\hline 6 & $\mathrm{~F}$ & Th1 & Leg & $A$ & III & $M R S A$ & 30 & 35 \\
\hline 7 & M & L1 & Ankle & $A$ & III & $M R S A$ & 20 & 51 \\
\hline 8 & $\mathrm{~F}$ & L1 & Sacrum & A & III & MRSA & 15 & 51 \\
\hline 9 & M & Th11 & Sacrum & $\mathrm{B}$ & III-IV & Entcoc, Prot. mib., E.coli. & 12 & 30 \\
\hline 10 & M & Th11 & Ischium & $A$ & III & Provid. stuwri. & 8 & 30 \\
\hline 11 & $\mathrm{~F}$ & Th10 & Sacrum & $A$ & III & E.coli., Staph. aur. & 10 & 49 \\
\hline 12 & $\mathrm{~F}$ & Th12 & Sacrum & $A$ & III-IV & E. coli. & 12 & 58 \\
\hline 13 & M & L1 & Sacrum & $A$ & III & $M R S A$ & 10 & 52 \\
\hline 14 & M & $\mathrm{C7}$ & Abdomen, & $A$ & III & Staph. epi. & 10 & 33 \\
\hline 15 & M & $\mathrm{C7}$ & Thigh & A & III & Staph. epi. & 20 & 33 \\
\hline 16 & $\mathrm{~F}$ & $\mathrm{C7}$ & Groin, ischium & A & IV & Pseud. aeru. & 10 & 50 \\
\hline 17 & $\mathrm{~F}$ & Th10 & Leg & $A$ & III & Enterb. cloa., Prot. mib. & 20 & 42 \\
\hline 18 & M & L1 & Sacrum & $\mathrm{B}$ & III & MRSA & 15 & 45 \\
\hline 19 & M & $\mathrm{C} 5$ & Heel & B & III & Pseud. aeru. & 20 & 40 \\
\hline 20 & $M$ & L1 & Sacrum & $A$ & III & $M R S A$ & 30 & 50 \\
\hline
\end{tabular}

Abbreviations: Entcoc., Enterococcus; Enterb. Cloa., Enterobacter cloacae; E. coli., Escherichia coli; F, female; Klebs. Pneumo., Klebsiella pneumoniae; M, male; MRSA, Methicillin-resistant Staphylococcus aureus; Prot. mib., Proteus mirabilis; Provid. stuwri., Providencia stuartii; Pseudo. aeru., Pseudomonas aeruginosa; Staph. aur., Staphylococcus aureus; Staph. epi., Staphylococcus epidermidis. 

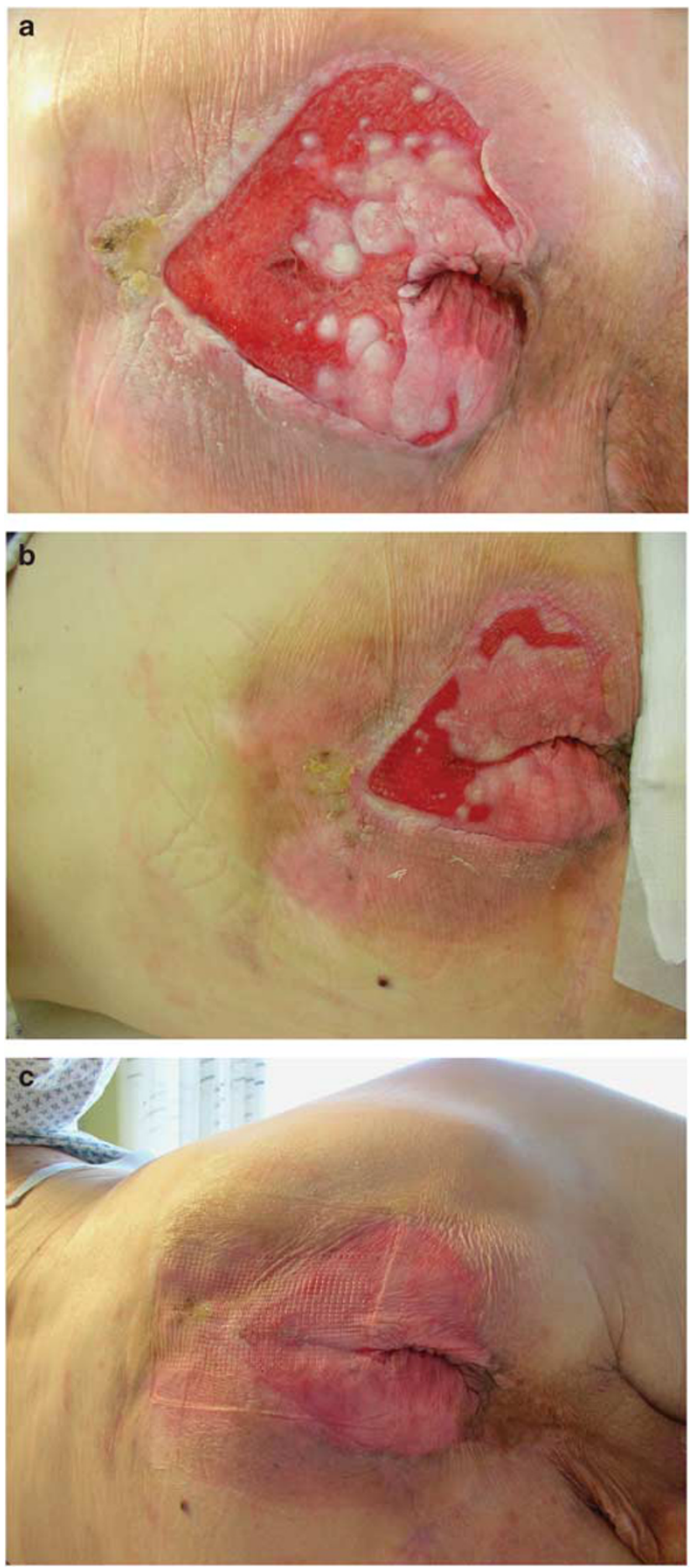

Figure 1 Patient number 1 (Table 1). A 79-year-old male paraplegic (Th4) patient with sacral ulcer grade 3 NPUAP. $^{6}$ (a) First photo documentation. (b) second photo, 2 weeks after Medihoney treatment. (c) Third photo, 4 weeks after Medihoney treatment.

medical honey wound treatment as one of many different therapeutic approaches.

Although additional prospective randomised studies on a variety of wounds are needed to confirm the safety and efficacy of medical honey, our study is consistent with current evidence ${ }^{7,9}$ that confirms the antibacterial properties and additional beneficial effects of medical
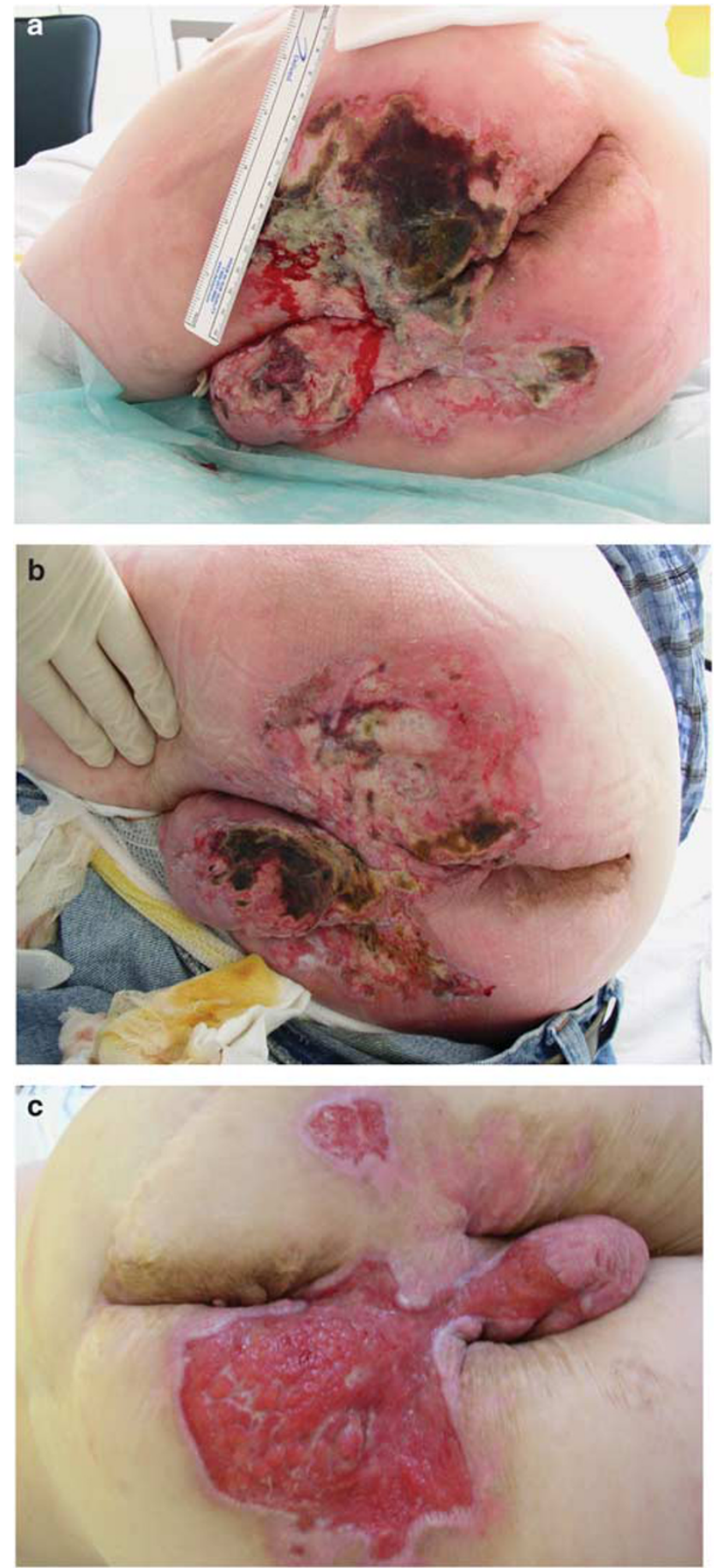

Figure 2 Patient number 2 (Table 1). A 35-year-old male paraplegic (Th1) patient with ischial and scrotal ulcer grade 3-4 NPUAP. ${ }^{6}$ (a) First photo documentation. (b) Second photo, after primary surgical debridement and 2-week Medihoney treatment. (c) Third photo, 4 weeks after Medihoney treatment.

honey on wound healing. The positive results of this study should encourage other wound-care professionals to implement the use of CE-certified honey dressings with standardised antibacterial activity into their professional wound-care regimen.

The available evidence indicates effective treatment for wound care. Reports from 17 randomised controlled trials involving a total of 1965 

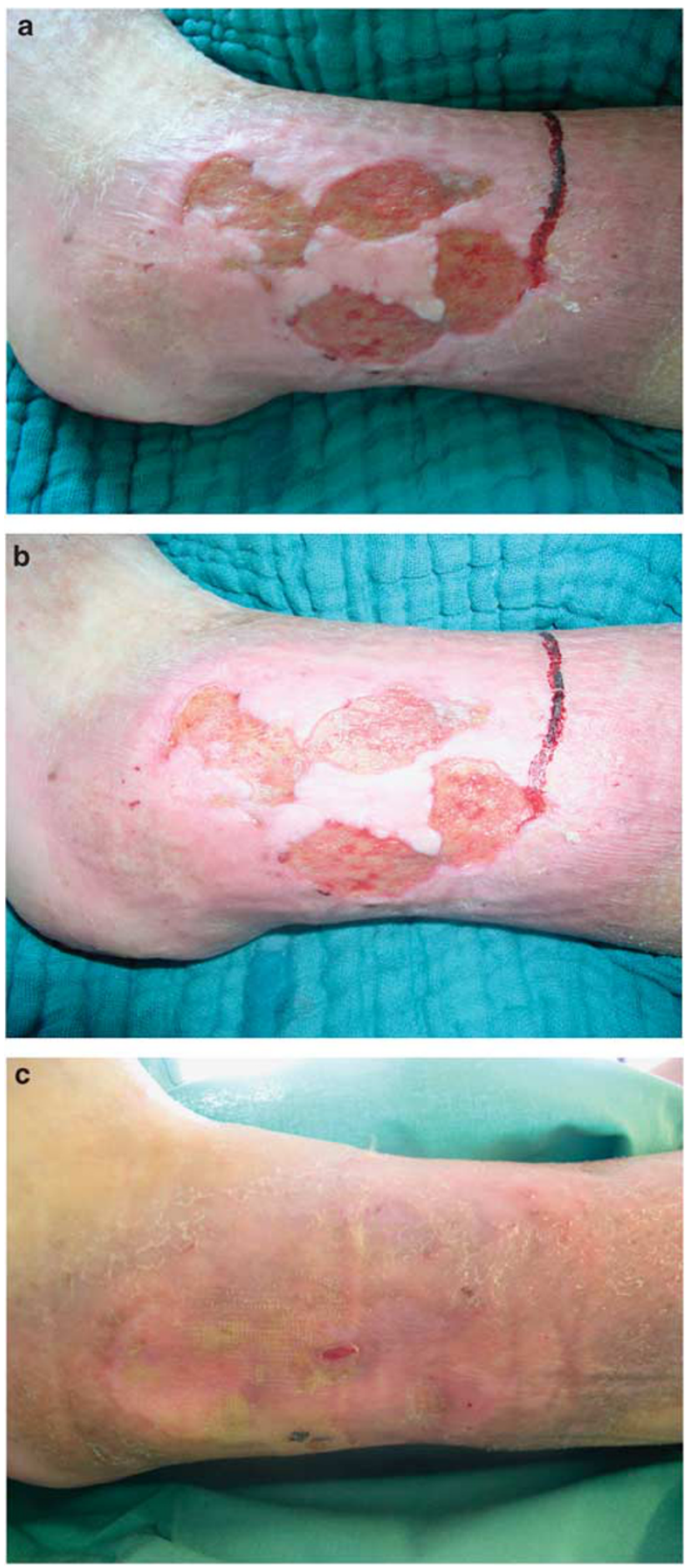

Figure 3 Patient number 7 (Table 1). A 51-year-old male paraplegic (L1) patient with ankle ulcer grade 3 NPUAP6 with Methicillin-resistant Staphylococcus aureus. (a) First photo documentation. (b) Second photo, 2 weeks after Medihoney treatment. (c) Third photo, 4 weeks after Medihoney treatment, with eradication of Methicillin-resistant Staphylococcus aureus.

participants and 5 clinical trials of other forms involving 97 participants, collectively demonstrate that honey is an effective treatment for wounds.

In addition, there is a large amount of supporting evidence for the use of honey in wound care from case studies. Clinicians often view honey as a novel and experimental wound treatment despite the large amount of evidence that establishes honey as a tested, safe and effective therapy. Clinicians who dismiss honey as non-scientific or not well-researched are encouraged to look for clinical evidence supporting the standard treatment they usually rely upon.

At the beginning of the honey treatment in our study, all PUs showed colonisation with various bacterial pathogens (Table 1). After 1 week of treatment with Medihoney, no residual bacteria were detected in wound swabs; even the decubitus initially colonised with Methicillin-resistant Staphylococcus aureus was effectively decolonised with Medihoney. Our study clearly demonstrated the antibacterial properties of honey by clearing the infections from all the PUs to which it was applied. The honey we used is known to have enhanced antibacterial action and has been shown in other clinical case studies to disinfect the wound and improve clinical wound healing. ${ }^{10}$

Dunford et al. ${ }^{11}$ conducted a four-centre feasibility study to determine whether Medihoney was an acceptable treatment for patients with leg ulcers in terms of pain relief, odour control and overall patient satisfaction. A total of 40 patients, whose leg ulcers had not responded to 12 weeks of compression therapy, were recruited. Medihoney dressings were applied to their ulcers for a 12-week study period. All other aspects of their care, including the use of compression bandaging, remained unchanged. Overall, ulcer pain and size decreased significantly, and odorous wounds were deodorised promptly with Medihoney treatment. Conversely, Jull et al. ${ }^{12}$ found that for chronic venous leg ulcers, honey did not significantly decrease the healing time, when used with compression bandaging. Further studies are needed to clarify the role of honey as an adjuvant therapy in the management of venous ulcers. In large acute wounds, such as burn wounds, however, Jull et al. ${ }^{12}$ concluded that honey might reduce healing time compared with some conventional dressings.

In the superficial and partial thickness wounds caused by burn injuries, honey has been shown to improve healing times. ${ }^{10,12}$ Wijesinghe et al. compared burns covered with a honey gauze with those covered with silver sulphadine-impregnated gauze in 624 subjects, with the primary end point being healing at 15 days. Honey proved to be more effective than silver, with a fixed effect odds ratio of 6.1 for healing at 14 days (95\% CI 3.7-9.9). Silver was significantly less effective in all secondary outcome measures. ${ }^{10,12}$

Medical honey dressings are non-adherent after rinsing with sterile Ringer's solution, easy to change without pain, and do not cause harm to the regenerating tissue. Malodour from recalcitrant wounds, as a result of critical colonisation and partial tissue necrosis, is successfully abolished with medical honey due to its antibacterial, anti-inflammatory and debriding effects. Medical honey can be used in all stages of wound healing, in many different types of wounds, and even in patients with diabetes.

Certainly, the medical honey approach to wound care must be part of a comprehensive, conservative and surgical wound-care concept. Patients with extended tissue necrosis require surgical debridement before medical honey is used. In patients with deep lokal soft tissue or with systemic infection, appropriate antimicrobial treatment is necessary in addition to local wound care.

Further, any comorbidity that contributes to the problems in wound healing should be diagnosed and treated thoroughly with state-of-the-art interventions (for example, bypass surgery in patients with reduced arterial perfusion, compressive bandages in patients with chronic venous ulcers, and sufficient control of blood glucose levels in patients with diabetic foot syndrome).

\section{CONCLUSION}

Our study, a clinical trial documenting wound healing with honey treatment as measured by bacterial growth, wound size and 
stage of healing, indicates that honey is highly effective in wound management.

Although minimal evidence can be found to discourage or restrict the application of medical honey to wounds, more studies are needed to establish universal clinical medical honey guidelines with regard to the size, type and age of the wounds best treated with medical honey to assure long-term safety and efficacy, and to uncover possible contraindications.

\section{CONFLICT OF INTEREST}

The authors declare no conflict of interest.

\section{ACKNOWLEDGEMENTS}

We thank Dr Ralph Hanano, who has been an authorised wound-care specialist representing Comvita, the manufacturer of Medihoney products during the study period in Germany. The study has been funded by a scientific grant from Comvita.

1 Johnson RL, Gerhart KA, McCray J, Menconi JC, Whiteneck GG. Secondary conditions following spinal cord injury in a population-based sample. Spinal Cord 1998; 36: 45-50.
2 Whiteneck GG, Charlifue SW, Frankel HL, Fraser MH, Gardner BP, Gerhart KA et al. Mortality, morbidity, and psychosocial outcomes of persons spinal cord injured more than 20 years ago. Paraplegia 1992; 30: 617-630.

3 Vangilder C, Macfarlane GD, Meyer S. Results of nine international pressure ulcer prevalence surveys: 1989 to 2005. Ostomy Wound Manage 2008; 54: 40-54.

4 Merckoll P, Jonassen TO, Vad ME, Jeansson SL, Melby KK. Bacteria, biofilm and honey: A study of the effects of honey on 'planktonic' and biofilm-embedded chronic wound bacteria. Scand J Infect Dis 2009; 41: 1-7.

5 Kramer A, Daeschlein G, Kammerlander G, Abdriessen A, Aspöck C, Bergemann R et al. consensus recommendation for the choice of antiseptic agents in wound care (article in german). Hygiene und Medizin 2004; 29: 147-157.

6 Edsberg L, Geyer MJ, Zulkowski K. The NPUAP support surface initiative. Adv Skin Wound Care 2005; 18: 164-166.

7 Molan PC. The evidence supporting the use of honey as a wound dressing. Int J Low Extrem Wounds 2006; 5: 40-54.

8 Isenberg H. Clinical Microbiology Procedures Handbook, vol. 1, 2 and 3, 2nd edn. American Society for Microbiology: Washington, DC, 2004.

9 Wahner-Roedler DL, Vincent A, Elkin PL, Loehrer LL, Cha SS, Bauer BA. Physicians' attitudes toward complementary and alternative medicine and their knowledge of specific therapies: a survey at an academic medical center. Evid Based Complement Alternat Med 2006; 3: 495-501.

10 Wijesinghe M, Weatherall M, Perrin K, Beasley R. Honey in the treatment of burns: a systematic review and meta-analysis of its efficacy. NZ Med J 2009; 122: 47-60.

11 Dunford CE, Hanano R. Acceptability to patients of a honey dressing for non-healing venous leg ulcers. J Wound Care 2004; 13: 193-197.

12 Jull AB, Rodgers A, Walker N. Honey as a topical treatment for wounds. Cochrane Database Syst Rev 2008; (4): CD0005083.

13 Frankel HL, Hancock DO, Hyslop G, Melzak J, Michaelis LS, Ungar GH et al. The value of postural reduction in the initial management of closed injuries of the spine with paraplegia and tetraplegia. I. Paraplegia 1969; 7: 179-192. 